Research Article

\title{
Barriers to Health Workers in Iron Deficiency Anemia Prevention among Indonesian Pregnant Women
}

\author{
Darmawati Darmawati $\left(\mathbb{D},{ }^{1,2}\right.$ Tongku N. Siregar ${ }^{(D)},{ }^{3}$ Hajjul Kamil ${ }^{(D)},{ }^{4}$ and Teuku Tahlil ${ }^{5}{ }^{5}$ \\ ${ }^{1}$ Graduate School of Mathematics and Applied Science, Universitas Syiah Kuala, Aceh 23111, Indonesia \\ ${ }^{2}$ Department of Maternity Nursing, Faculty of Nursing, Universitas Syiah Kuala, Aceh 23111, Indonesia \\ ${ }^{3}$ Faculty of Veterinary, Universitas Syiah Kuala, Aceh 23111, Indonesia \\ ${ }^{4}$ Department of Management Nursing, Faculty of Nursing, Universitas Syiah Kuala, Aceh 23111, Indonesia \\ ${ }^{5}$ Department of Community Nursing, Faculty of Nursing, Universitas Syiah Kuala, Aceh 23111, Indonesia \\ Correspondence should be addressed to Darmawati Darmawati; darmawati.fkep@unsyiah.ac.id
}

Received 7 June 2020; Revised 21 September 2020; Accepted 16 December 2020; Published 24 December 2020

Academic Editor: Gunanidhi Dhangadamajhi

Copyright ( 2020 Darmawati Darmawati et al. This is an open access article distributed under the Creative Commons Attribution License, which permits unrestricted use, distribution, and reproduction in any medium, provided the original work is properly cited.

\begin{abstract}
Background. Anemia is a global maternal health problem that commonly occurs in developing countries. During pregnancy, a woman will receive antenatal services to check her condition and prevent complications. This study aimed to explore barriers towards achieving eradication of iron deficiency anemia among pregnant women in Aceh Besar District, Indonesia. Methods. This qualitative study was conducted on 18 health workers who were recruited through a purposive sampling method. Data were collected through in-depth interviews using open-ended questions to gain insight about participants' experiences in managing iron deficiency anemia among pregnant women. Data analysis was conducted by an inductive content analysis method to evaluate, encode, and analyze the interview's result. Result. Three main themes emerged: (1) facilities, infrastructures, and supplement support; (2) sociocultural factors; and (3) health provider competency deficits and no developing guidelines. Conclusion. Our findings provide understanding that there are many obstacles and barriers encountered by health workers in iron deficiency anemia prevention management. Thus, the management of anemia must be supported by a skilled health worker and quality facilities. Health workers and pregnant women must work together to achieve optimal management of anemia prevention.
\end{abstract}

\section{Introduction}

Anemia during pregnancy is a major health problem that often occurs in developing countries, and this situation can cause negative effects on pregnancy [1]. Anemia is a risk factor that contributes to $50 \%$ of maternal deaths [2]. The World Health Organization (WHO) defines a pregnant woman is classified into anemia if her hemoglobin $(\mathrm{Hb})$ level is less than $11 \mathrm{gr} / \mathrm{dl}$ [3]. Globally, anemia in pregnancy is a severe hematologic disorder affecting 32.4 million pregnant women [4]. According to the WHO, anemia is considered to be a significant health problem if its prevalence in a study population is $5.0 \%$ or more. The prevalence of anemia $\geq 40 \%$ in a population is classified as a severe public health problem [5]. Currently, Indonesian prevalence of anemia during pregnancy in 2018 was $48.9 \%$; this number increased from the last 5 years which was $37.1 \%[6,7]$, with the prevalence in Aceh Besar district being 37.1\% [8]. This condition is quite worrying, so it needs actions and research studies that can be used to overcome this problem. A study conducted by Woldegebriel et al. found that the maternal age, education, family income, religion, number of family members at home, and number of children were determinant factors that contribute to anemia in pregnancy [9].

Iron deficiency is the commonest nutritional problem causing anemia among pregnant women [10]. Half of all the cases of anemia can be attributed to iron deficiency [11]. Iron deficiency anemia (IDA) during pregnancy is associated with adverse health effects, including low birth weight and preterm birth. Iron deficiency at giving birth is also 
associated with developmental delays in children [12]. Also, adverse effects felt by the mother include fatigue, decreased body's immune system functions, poor work capacity, increased risk of heart disease, and death [13-15]. A study also showed that anemia during pregnancy contributed to $23 \%$ of indirect causes of maternal death in developing countries [13]. Due to the significant influence of anemia during pregnancy on maternal death, this condition must be treated immediately. This is also in line with one of the targets in Sustainable Development Goals (SDGs) which try to reduce maternal mortality until less than 70 per 100,000 live births in 2030 [16].

Pregnant women must prepare properly for their pregnancy and receive adequate antenatal care. Antenatal care is a program that becomes a way for pregnant women to know their condition so that health workers may be able to provide services based on what they need [2]. Previous studies also found that the quality of antenatal care and number of visits can prevent anemia during the prenatal period [17]. It shows that the role of quality antenatal care in preventing anemia cannot be ruled out [18]. During this time, the Indonesian Ministry of Health has been trying to improve the quality of antenatal services provided to pregnant women. Currently, antenatal care standards that apply in Indonesia consist of 11 procedures that must be met by health workers [19]. The procedures are (1) weight measurement, (2) upper arm circumference measurement, (3) blood pressure measurement, (4) fundal height measurement, (5) fetal heart rate measurement, (6) determine fetal presentation, (7) provide tetanus toxoid immunization, (8) provide iron tablet, (9) provide laboratory test, (10) provide referral properly, and (11) provide health education.

So far, the general antenatal services provided have not been able to manage anemia in pregnancy comprehensively. This is evidenced by the prevalence of anemia that tends not to decrease. The reason why this procedure cannot overcome the pregnancy complications is still not clear enough. Previous studies have not examined barriers perceived by health workers in undergoing IDA prevention management among pregnant women. More insight about these barriers needs to be studied more deeply, so it can support policymaking to improve the quality of antenatal care and suits the needs of pregnant women. The purpose of this study was to explore barriers towards achieving eradication of iron deficiency anemia among pregnant women in Aceh Besar District, Indonesia.

\section{Materials and Methods}

We used a qualitative method with in-depth interviews to explore the barriers perceived by health workers regarding IDA prevention management among pregnant women. The data were collected in Public Health Centers (PHCs) in Aceh Besar District, Indonesia. In total, there are 28 PHCs in this area. This study was done at 9 selected PHCs in Aceh Besar district and selected using a simple random sampling method. The participant recruitment process was done using purposive sampling methods. The purpose was to recruit participants using inclusion criteria, which were health workers with a minimum diploma level of education, worked at the selected Public Health Center, and responsible for the Mother and Child Health Department. There were 18 health workers who met these criteria and participated in this study.

In-depth interviews were conducted using open-ended questions. The questions used in this study include the following: (1) what is the incidence of anemia in your work area? (2) What are the PHC programs related to the management of anemia in pregnant women? (3) So far, what are the obstacles faced by health workers in managing and preventing anemia among pregnant women? (4) Do PHC have a special counseling program for pregnant women about anemia that been designed at this PHC? (5) What do you think if anemia counseling is designed separately from other conditions during pregnancy? (6) Have you previously trained to be an anemia counselor? (7) What do you think if there is a health worker who is prepared to do counseling about anemia in pregnant women? (8) Are there any suggestions from you to minimize the obstacles found in managing and preventing anemia in pregnant women? The data collection process started with recruiting participants from the selected PHCs. After informed consent was obtained and the participants agreed to participate in the study, interview began. The interview was held for 45-60 minutes. All information from the interview was recorded with digital voice recorders and noted by hand. Interviews were held in the health center hall to minimize noise. After a number of participants were obtained, data collection was stopped because no more new themes were found, so we concluded the data saturation had been achieved.

The inductive content analysis (ICA) method was used to evaluate, encode, and analyze the results of verbal interviews. The results of interviews and discussions were listened several times before being written into a transcript. After that, the results of the transcript were read several times to get a good contextualized understanding. Furthermore, a list of categories and subthemes was developed based on research objectives to answer the whole research questions [20]. Another investigator independently reviewed and verified these categories and subthemes. This study was approved by the Ethics Committee of the Nursing Faculty, Universitas Syiah Kuala, Aceh, with code number 1130041111218.

\section{Results}

In this study, the majority of the participants was midwife and had experience in providing health services, especially antenatal care for pregnant women (Table 1). The codes were classified into themes, categories, and subcategories. In the process of analyzing qualitative data after categorizing the code and removing the same code, 12 codes were obtained in 10 subcategories, 7 categories, and 3 main themes, which were facilities, infrastructures, and supplement support; sociocultural factors; and health provider competency deficits and no developing guidelines (Table 2). 
TABLE 1: Characteristics of participants.

\begin{tabular}{lcc}
\hline Characteristics & $n=18$ & $\%$ \\
\hline Age & & \\
$\quad<40$ years old & 4 & 22.2 \\
$\quad 40-50$ years old & 13 & 72.2 \\
$\quad>50$ years old & 1 & 5.6 \\
\hline Education & & \\
$\quad$ Diploma & 9 & 50 \\
Bachelor of Public Health & 3 & 16.7 \\
Master of Public Health & 2 & 11.1 \\
$\quad$ Medical degree & 3 & 16.7 \\
$\quad$ Bachelor of Dentistry & 1 & 5.5 \\
\hline Practical experience & & \\
$\quad<20$ years & 12 & 66.7 \\
$\quad>20$ years & 6 & 33.3 \\
\hline
\end{tabular}

3.1. Facilities, Infrastructures, and Supplement Support. Health workers in this study revealed that they felt the facilities and infrastructure in IDA prevention management were inadequate. They stated that the place being not appropriate and not specific becomes the inhibiting factors for the counseling process, as they said:

"During this time, counseling is done in the nutrition room. Actually, the room is very narrow and uncomfortable for counseling. Sometimes it also feels hot, too." (P2)

Most of the participants revealed that only general funds were provided for maternal and child health. There were no special funds for the treatment of iron deficiency anemia. These limited funds were barriers for them in providing services to prevent iron deficiency anemia among pregnant women, as they said:

"The first obstacle may be from the funds..." (P6)

"Another obstacle I think is about the funds. There are funds but for the mother and child health overall, there are no special funds for anemia." (P4)

Some health workers stated that there were no clear calculations for the availability of iron tablets and hemoglobin measuring devices. As a result, there are too many iron tablets that have expired, and one component of the hemoglobin examination tool was not enough, which was the strips.

"For iron tablets, there are many in our place (in the Public Health Center). But because it supplied too much, so many of them now are out of date." (P7)

"Yes, we have the $\mathrm{Hb}$ meter tools. But the sticks aren't available. The amount is not enough." (P11)

3.2. Sociocultural Factors. Most of the participants revealed that the behavior of pregnant women and families poses a special obstacle for health workers to make sure they follow the advice stated by health workers. This sociocultural factor was very strongly held by pregnant women and their families. They had incorrect views in consuming iron tablets so that they become not compliance in consuming them, as they said:

"Most of the behavior is not compliance in consuming iron tablets." (P1)

"I know they think they are given medicine, not supplements, they consider themselves not sick so they do not want to consume drugs. .." (P4)

In addition to the view of iron supplementation, the majority of participants also revealed that pregnant women continue to consume the wrong foods during pregnancy, which were foods that can inhibit iron absorption and trigger anemia, as they said:

"Many pregnant women drink coffee or tea. Even though she was told not to drink it during pregnancy. But they still drink." (P10)

Participants in this study also stated that there was a wrong view of society in perceiving a woman's pregnancy. Many pregnant women feel ashamed if their pregnancy is known to other people, and the husband also felt embarrassed to accompany a pregnant wife to do a pregnancy checkup, as they said:

"When she was in the first trimester of pregnancy, she was hiding from health workers, decided not to do a pregnancy check because they were shy if people found out she was pregnant. So, they did not get iron tablets in the first trimester.” (P2)

"Pregnant women are rarely accompanied by her husband. Maybe only one or two, but most of what I have seen so far, their husbands do not accompany. It is because they embarrassed because their wives are pregnant." (P15)

Related to social factors, participants revealed that most of the husbands worked as fishermen. However, the work results are not provided as food sources for his family, but sold and replaced with other foods; they even bought instant noodles, as stated by the participants:

"The catch (the work result as a fisherman) was immediately sold and, if possible, they would not eat the fish for even one piece. The money earned is used to buy other foods, such as indomie (instant noodles)." (P9)

3.3. Health Provider Competency Deficits and No Developing Guidelines. The majority of participants in this study revealed that there were no specific guidelines on anemia management for counselors. The counseling that was carried out was general counseling with the guidance of the Mother and Child Health book published by the Indonesian Ministry of Health, as they said: 
TABLE 2: Major findings with code, subcategories, categories, and themes.

\begin{tabular}{|c|c|c|c|}
\hline Code & Subcategory & Category & Theme \\
\hline $\begin{array}{l}\text { Inadequate counseling room } \\
\text { Limited funds for the } \\
\text { management of anemia }\end{array}$ & $\begin{array}{l}\text { Inappropriate and unspecified } \\
\text { places inhibit the counseling } \\
\text { process } \\
\text { There are no specific funds } \\
\text { available for anemia treatment }\end{array}$ & $\begin{array}{l}\text { Inadequate infrastructure in iron } \\
\text { deficiency anemia prevention } \\
\text { management }\end{array}$ & $\begin{array}{c}\text { Facilities, infrastructures, and } \\
\text { supplement support }\end{array}$ \\
\hline $\begin{array}{l}\mathrm{Hb} \text { tool components are not } \\
\text { sufficient }\end{array}$ & $\begin{array}{l}\text { Inadequacy of the } \mathrm{Hb} \text { tool } \\
\text { component }\end{array}$ & & \\
\hline $\begin{array}{l}\text { The available iron tablets have } \\
\text { expired }\end{array}$ & $\begin{array}{l}\text { Incorrect calculation of iron } \\
\text { tablet supply }\end{array}$ & Inadequate supplement supply & \\
\hline $\begin{array}{l}\text { Noncompliance for iron } \\
\text { consumption } \\
\text { Eating the wrong food } \\
\text { Embarrassed if the pregnancy is } \\
\text { known by others }\end{array}$ & $\begin{array}{l}\text { The behavior of pregnant } \\
\text { women in consuming iron }\end{array}$ & An incorrect view of iron needs & Sociocultural factors \\
\hline $\begin{array}{l}\text { Ashamed if accompanying a } \\
\text { pregnant wife }\end{array}$ & $\begin{array}{l}\text { Community perception about } \\
\text { pregnancy }\end{array}$ & $\begin{array}{l}\text { The wrong culture related to } \\
\text { pregnancy }\end{array}$ & \\
\hline $\begin{array}{l}\text { Exchange iron-containing work } \\
\text { results with nonnutritious foods }\end{array}$ & $\begin{array}{c}\text { Food sources of iron are not } \\
\text { consumed by the family }\end{array}$ & Bad behavior towards family & \\
\hline $\begin{array}{l}\text { Anemia counselors are not } \\
\text { trained }\end{array}$ & $\begin{array}{l}\text { There are no trained health } \\
\text { workers to become anemia } \\
\text { counselors }\end{array}$ & $\begin{array}{l}\text { Health workers' knowledge and } \\
\text { competence }\end{array}$ & $\begin{array}{c}\text { Health provider competency } \\
\text { deficits and no developing } \\
\text { guidelines }\end{array}$ \\
\hline $\begin{array}{l}\text { Incompatibility of staff } \\
\text { competence in the management } \\
\text { of anemia }\end{array}$ & $\begin{array}{l}\text { Incompatibility of health } \\
\text { workers' competencies }\end{array}$ & & \\
\hline $\begin{array}{l}\text { No specific guidelines for } \\
\text { anemia counseling }\end{array}$ & No special guidebook available & $\begin{array}{l}\text { Specific guidelines for anemia } \\
\text { counselors }\end{array}$ & \\
\hline
\end{tabular}

"There is a guideline for counseling, only from maternal and child health books. The book is general for all conditions during pregnancy, not specific for anemia." (P5)

Participants also revealed that there were no special health workers who became anemia counselors. Counselors who have been conducting counseling so far were nutritionists who had never undergone counseling training, including anemia counseling training, as they stated:

"The person who did the counseling is nutritionist. They have never been trained about counseling, especially for the counseling about anemia." (P12)

Some participants said that counseling was not carried out by health workers who examined pregnant women, but by the nutrition department. The counseling process was carried out by nutritionists after other health workers examined pregnant women in the Maternal and Child Health room, as they said:

"Counseling is usually done by a nutritionist. After getting the conditions of what happens to pregnant women, we collaborate with nutritionists." (P13)

\section{Discussion}

In the present study, it was found that there were obstacles that were complained by health workers in managing problems in pregnancy, especially anemia. They realized that anemia was a problem that must be handled. However, health workers feel they did not have adequate facilities and infrastructure, felt inadequate, and did not have complete clinical guidelines to manage anemia in pregnancy. The results of this study were supported by the previous study conducted by Widyawati et al. who found that insufficient facilities, high work load, lack of training opportunities, and learning resources for the health care providers are obstacles found in preventing anemia during pregnancy in the PHC [21].

The inadequacy of facilities and infrastructure that support a service in overcoming a health problem was an aspect that should receive more attention. A literature study conducted by Manyisa and van Aswegen found that inadequate infrastructure and resources were the main factors contributing to the decline of the health service quality [22]. Other research also found that poor funding budgets were a major challenge in providing quality health services [23]. The reality that occurs was very contradictory to government programs that seek to reduce maternal mortality rates through improvements in antenatal care standards that have been carried out so far [19]. Improvement of health services, facilities, and financial support should be done especially in the management of anemia because this situation is one of the global health problems that contributes to increasing maternal mortality.

Besides the ineffectiveness of facilities and infrastructure, cultural beliefs held by pregnant women and their families regarding pregnancy were also an obstacle for health 
workers in conveying health information. A study proved that cultural beliefs that are believed to be true will affect a pregnant woman's daily life [24]. To make pregnant women and their families follow the advice stated by health workers, it is important for health workers to have effective communication with them and their families. When effective communication has established a trusting relationship, it will be easier for them to convey information by aligning cultural beliefs that are believed by pregnant women. When this trust is not built up, pregnant women will be closed and tend not to respect the information provided. It would be better if the pregnant woman was accompanied by her husband or close family so that the information would be conveyed thoroughly. A husband who accompanies his wife when receiving health services will positively correlate with the woman's own behavior in internalizing health-related advice. It is because as the main decision maker in the household, the husband will play a big role in all aspects including the behavior of seeking health assistance [25]. However, a literature study conducted by Chang et al. revealed that, in building a mutual trust relationship, it will also be influenced by the social status of pregnant women, the environment, the number of health workers, and their cultural beliefs [26].

In addition to barriers from facilities and clients, health workers also pointed out that while undergoing their role as information providers to pregnant women, they never had specific guidelines, especially when providing counseling about anemia. They have also never been trained how to do the right counseling. Previous research also found that the lack of quality health services to pregnant women is influenced by the ineffectiveness of work placement of health workers, lack of training opportunities, and learning resources [21]. Increased knowledge and quality of service by health workers are needed. Training programs must be specifically designed to demonstrate and enhance the knowledge and skills of health workers. Furthermore, it must be reevaluated after the training is done. It is done to ensure that good quality health services can still be provided by health workers, especially related to anemia management, so that this condition can be prevented earlier [27]. The training provided must also be able to run effectively. A study conducted by Naeem suggested that it is necessary to refresh knowledge regularly and periodically so that the knowledge possessed is not forgotten and can be updated according to the needs of pregnant women [28].

Overall, this study found important information about barriers perceived by health workers in managing and preventing iron deficiency anemia among pregnant women. Many barriers perceived by health workers can be used as a supporting reference for policy makers at the Public Health Center to make a comprehensive improvement in the management of anemia, both in terms of health care facilities and the ability of health workers. However, there are some limitations in this study. Additional interviews conducted with health workers will enrich the data. In addition, interviews with policy and decision makers at the Public Health Center will also help to explore this issue.

\section{Conclusion}

The effectiveness of managing and preventing iron deficiency anemia in pregnancy is influenced by factors that actually inhibit its application. So far, health workers have experienced many problems in managing anemia in primary care, such as inadequate facilities and infrastructure, incompetent staff, and inhibiting factors from pregnant women and their families. Based on our research findings, we conclude that health providers who provide antenatal care to pregnant women, especially in the management of iron deficiency anemia, need to be cared for and minimize the obstacles found so that the services provided can be more adequate.

\section{Data Availability}

The data used to support the findings of this study are available from the corresponding author upon request.

\section{Disclosure}

This manuscript is part of requirement in fulfillment of the doctoral study.

\section{Conflicts of Interest}

The authors declare that there are no conflicts of interest regarding the publication of this paper.

\section{Authors' Contributions}

The main author (DD) was the person who conducted the research and wrote the principal draft of the manuscript. Quotes have been selected to illustrate the themes that emerged from the interviews and have been translated into English. NT, KH, and TT was the team that corrected each writing, directed the design of the study, supervised the research conducted, and revised the text. Furthermore, all authors read and approved the manuscript.

\section{Acknowledgments}

The authors would like to acknowledge the health care providers who participated and shared their perceptions in this study. They also thank Aceh Besar District Health Office for granting permission and facilitating this study. The authors are very thankful to Elly Wardani who assisted in question design and data triangulation, as well as the contribution from Masyithah Audina.

\section{References}

[1] G. Stephen, M. Mgongo, T. Hussein Hashim, J. Katanga, B. Stray-Pedersen, and S. E. Msuya, "Anemia in pregnancy: prevalence, risk factors, and adverse perinatal outcomes in Northern Tanzania," Anemia, vol. 2018, Article ID 1846280, 9 pages, 2018.

[2] T. T. Darmawati, T. N. Siregar, H. Kamil, and M. Audina, "Antenatal care and iron deficiency anemia among pregnant women," in Proceeding 8th AIC Health Life Sciences 
2018-Syiah Kuala University, pp. 13-24, Banda Aceh, Indonesia, September 2018.

[3] World Health Organization, Iron Deficiency Anemia: Assessment, Prevention and Control, World Health Organization, Geneva, Switzerland, 2001.

[4] W. W. Takele, A. Tariku, F. W. Shiferaw, A. Demsie, W. G. Alemu, and D. Z. Anlay, "Anemia among women attending antenatal care at the University of Gondar comprehensive specialized referral hospital, northwest Ethiopia," Anemia, vol. 2018, Article ID 7618959, 2017.

[5] World Health Organization, Worldwide Prevalence of Anemia 1993-2005: WHO Global Database on Anemia, World Health Organization, Geneva, Switzerland, 2008.

[6] Indonesian Ministry of Health, Hasil Utama Riset Kesehatan Dasar 2018 (Main Results of Basic Health Research 2018), Research and Development Department, Indonesian Ministry of Health, Jakarta, Indonesia, 2018.

[7] Indonesian Ministry of Health, Riset Kesehatan Dasar 2013, Research and Development Department, Indonesian Ministry of Health, Jakarta, Indonesia, 2013.

[8] Aceh Besar District Public Health Office, Aceh Besar District Public Health Profile 2017, Aceh Besar District Public Health Office, Aceh, Indonesia, 2017.

[9] A. G. Woldegebriel, G. Gebregziabiher Gebrehiwot, A. Aregay Desta et al., "Determinants of anemia in pregnancy: findings from the Ethiopian health and demographic survey," Anemia, vol. 2020, Article ID 2902498, 9 pages, 2020.

[10] G. C. Di Renzo, "Good clinical practice advice: iron deficiency anemia in pregnancy," International Journal of Gynecology \& Obstetrics, vol. 144, pp. 322-324, 2019.

[11] B. Abdella, M. Ibrahim, I. Tadesse, K. Hassen, and M. Tesfa, "Association between Helicobacter pylori infection and occurrence of anemia among pregnant women attending antenatal care in Kulito health center, halaba zone, south Ethiopia, 2018," Anemia, vol. 2020, Article ID 6574358, 2020.

[12] Helmy, N. I. Elkhouly, and R. A. Ghalab, "Maternal anemia with pregnancy and its adverse effects," Menoufia Medical Journal, vol. 31, pp. 7-11, 2018.

[13] R. E. Black, C. G. Victora, S. P. Walker et al., "Maternal and child undernutrition and overweight in low-income and middle-income countries," Lancet, vol. 382, pp. 427-451, 2013.

[14] G. A. Stevens, M. M. Finucane, L. M. De-Regil et al., "Global, regional, and national trends in hemoglobin concentration and prevalence of total and severe anemia in children and pregnant and non-pregnant women for 1995-2011: a systematic analysis of population-representative data," Lancet Global Health, vol. 1, pp. 16-25, 2013.

[15] M. A. Mbule, Y. B. Byaruhanga, M. Kabahenda, and A. Lubowa, "Determinants of anemia among pregnant women in rural Uganda," Rural Remote Health, vol. 13, no. 2, p. 2259, 2013

[16] IAEG-SDGs, "Final list of proposed sustainable development goal indicators," Report of the Inter-Agency and Expert Group on Sustainable Development Goal Indicators, pp. 1-25, 2016.

[17] E. M. Ikeanyi and A. I. Ibrahim, "Does antenatal care attendance prevent anemia in pregnancy at term Ikeanyi E M, Ibrahim A I-Niger," Journal of Clinical Practice, vol. 18, pp. 323-328, 2015.

[18] O. A. Idowu, C. F. Mafiana, and S. Dapo, "Anemia in pregnancy: a survey of pregnant women in Abeokuta, Nigeria," African Health Sciences, vol. 5, pp. 295-299, 2005.

[19] Indonesian Ministry of Health, Guidelines for Integrated Antenatal Care, Ministry of Health, Republic of Indonesia,
General Director of Community Health, Jakarta, Indonesia, 2010.

[20] M. Vaismoradi, J. Jones, H. Turunen, and S. Snelgrove, "Theme development in qualitative content analysis and thematic analysis," Journal of Nursing Education, vol. 6, pp. 100-110, 2016.

[21] W. Widyawati, S. Jans, S. Utomo, J. van Dillen, and L. L. M. L. Janssen, "A qualitative study on barriers in the prevention of anemia during pregnancy in public health centres: perceptions of Indonesian nurse-midwives," $B M C$ Pregnancy Childbirth, vol. 15, pp. 1-8, 2015.

[22] Z. M. Manyisa and E. J. van Aswegen, "Factors affecting working conditions in public hospitals: a literature review," International Journal of Africa Nursing Sciences, vol. 6, pp. 28-38, 2017.

[23] I. Yunusa, G. Suberu, D. Timothy et al., "Trends and challenges of public health care financing system in Nigeria: the way forward," IOSR Journal of Economics and Finance, vol. 4, pp. 28-34, 2014.

[24] Y. Agus, S. Horiuchi, and S. E. Porter, "Rural Indonesia women's traditional beliefs about antenatal care," BMC Research Notes, vol. 5, 2012.

[25] A. E. Rahman, J. Perkins, S. Islam et al., "Knowledge and involvement of husbands in maternal and newborn health in rural Bangladesh," BMC Pregnancy Childbirth, vol. 18, pp. 1-12, 2018.

[26] Y. Chang, K. Coxon, A. Gerarda, M. Furuta, and D. Bick, "Interventions to support effective communication between maternity care staff and women in labor: a mixed-methods systematic review," Midwifery, vol. 59, 2017.

[27] S. Bardosono, R. Hildayani, D. N. Chandra, R. W. Basrowi, and Y. Wibowo, "The knowledge retention after continuing health education among midwives in Indonesia," Medical Journal of Indonesia, vol. 27, pp. 60-65, 2018.

[28] N. Naeem, "Which knowledge and skills do participants retain after attending medical education training workshops?" Creatnet Education, vol. 07, pp. 870-877, 2016. 